\title{
Produção de alface em condições de salinidade a partir de mudas produzidas com e sem estresse salino
}

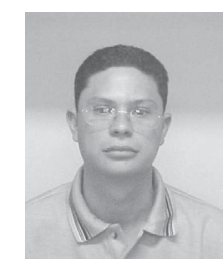

\author{
Sergio B.A. Viana ${ }^{1}$, Luis N. Rodrigues ${ }^{2}$, Pedro D. Fernandes ${ }^{3}$ \& Hans R. Gheyi ${ }^{4}$ \\ 1 DEAg/CCT/UFPB. Fone: (83) 333-8232, E-mail: sergioviana@globalmail.com.br (Foto) \\ 2 Escola Agrotécnica de Castanhal. E-mail: gabinete@eafc-pa.gov.br \\ ${ }^{3}$ DEAg/CCT/UFPB, CP 10.087, CEP 58109-970, Campina Grande, PB. Fone: (83) 310-1285. E-mail: pdantas@deag.ufpb.br \\ ${ }^{4}$ DEAg/CCT/UFPB. Fone: (83) 310-1056. E-mail: hans@deag.ufpb.br \\ Protocolo 099 - 14/08/2000
}

\begin{abstract}
Resumo: Objetivando-se estudar o efeito da salinidade da água de irrigação sobre a produção da alface cv. 'Elba', conduziu-se um experimento em ambiente protegido, no delineamento inteiramente casualizado, testando-se cinco níveis de condutividade elétrica da água de irrigação $\left(\mathrm{CE}_{a}: 0,3\right.$, $1,0,1,7,2,4$ e $3,1 \mathrm{dS} \mathrm{m}^{-1}$, a $25^{\circ} \mathrm{C}$ ) e dois tipos de mudas (produzidas com água de 0,3 e $3,1 \mathrm{dS} \mathrm{m}^{-1}$ ). Foram avaliados os efeitos sobre as variáveis fitomassa verde e seca da parte aérea, número de folhas, diâmetro da cabeça e fitomassa seca de raízes. Concluiu-se que a maioria das variáveis estudadas foi influenciada tanto pelo efeito da concentração de sais na água de irrigação como pelo fator tipo de muda sem, entretanto, haver efeito interativo dos fatores. No trabalho são apresentadas equações, obtidas através de regressão polinomial, relacionando as variáveis estudadas com os níveis de salinidade. O rendimento relativo final da cultivar estudada, em termos de fitomassa fresca, decresce 9,0\% para cada incremento unitário de CEa.
\end{abstract}

Palavras-chave: ambiente protegido, fitomassa, rendimento, Lactuca sativa L.

\section{Production of lettuce under salinity conditions using seedlings produced with and without saline stress}

\begin{abstract}
With the objective of studying the effect of water salinity on the productivity of lettuce, cv. 'Elba', an experiment was carried out in a completely randomized design, under a protected environment. Five levels of water salinity $\left(\mathrm{EC}_{\mathrm{w}}: 0.3,1.0,1.7,2.4\right.$ and $3.1 \mathrm{dS} \mathrm{m}^{-1}$ at $25^{\circ} \mathrm{C}$ ) and two types of seedlings (produced using water of 0.3 and $3.1 \mathrm{dS} \mathrm{m}^{-1}$ ) were tested. The effects of the factors on the fresh and dry weight of the aerial parts, number of leaves, diameter of the head, and dry weight of roots, were evaluated. It was concluded that the studied variables were influenced by $\mathrm{EC}_{\mathrm{w}}$ and by the seedling types, without being influenced by the factor interaction. The equations, obtained through polynomial regression, relating the variables studied with the salinity levels are also, presented. The relative production (fresh weight) of the cultivar studied, decreased $9.0 \%$ for each unitary increment of $\mathrm{EC}_{w}$.
\end{abstract}

Key words: protected environment, phytomass, yield, Lactuca sativa L.

\section{INTRODUÇÃO}

A crescente demanda por alimentos tornou o uso da irrigação imperativo em todo o mundo, sobretudo em regiões semi-áridas, como as do Nordeste brasileiro, onde ocorre déficit hídrico na maior parte do ano. É imprescindível o uso de irrigação nessas áreas, para se garantir uma boa produção agrícola, principalmente de cultivos exigentes em água, como é o caso da alface.

Apesar dos benefícios da irrigação, é preciso considerar que a água contém sais solúveis e seu uso indevido, na ausência de lixiviação, tem provocado a salinização de solos, reduzindo o crescimento/desenvolvimento das plantas (Fageria et al.,
1981), por baixar o potencial osmótico da solução do solo, causando estresse hídrico e, também, por ocasionar problemas de toxicidade e de desordem nutricional (Fageria, 1989). Embora a irrigação seja prática milenar, a preocupação com a qualidade da água só começou a ser reconhecida a partir do início deste século (Wilcox \& Durum, 1967).

Em diversos países, as áreas salinizadas vêm sendo exploradas com sucesso, graças à utilização de espécies tolerantes à salinidade e à adoção de práticas adequadas de manejo da cultura, do solo e da água (Araújo Filho et al., 1995). Fageria (1989) enfatiza a importância da utilização de culturas tolerantes à salinidade, como uma das soluções para a reincorporação de áreas salinizadas ao cenário produtivo. 
Estudos sobre os efeitos da salinidade no rendimento das culturas têm sido apresentados por vários autores (Maas \& Hoffman, 1977; Ayers \& Westcot, 1991, dentre outros). Conforme Maas \& Hoffman (1977), o incremento unitário de condutividade elétrica do extrato de saturação acima de $1,3 \mathrm{dS} \mathrm{m}^{-1}$ ocasiona $13 \%$ de decréscimo de rendimento na alface, sendo a cultura considerada 'moderadamente sensível' à salinidade. Vale ressaltar, entretanto, que essa classificação é relativa, por depender das condições ambientais e da planta (fase fenológica, estado nutricional etc.), inclusive podendo variar entre cultivares de uma mesma espécie (Maas \& Hoffman, 1977).

No Brasil, apesar da importância da alface que, já em 1986, era a sexta hortaliça em valor de produção e a oitava em termos de volume produzido (Nadal et al., 1986), são poucos os trabalhos de pesquisa envolvendo os efeitos do estresse salino nesta espécie. Em condições do Nordeste brasileiro, onde as cultivares do grupo da alface 'crespa solta' são as mais consumidas, não se encontrou, na literatura, qualquer referência a resultados de pesquisa envolvendo aspectos de salinidade em seu cultivo. Os poucos estudos existentes, em nível nacional, relacionados ao estresse salino, foram recentemente realizados na região sudeste (Ferreira et al., 1998; Blanco et al., 1999; Gervásio et al., 2000) onde, além de serem distintas as condições ambientais, também diferentes são as variedades cultivadas, predominando, naquela região do país, o cultivo de alface do 'grupo manteiga' (Filgueira, 1982).

Normalmente, as plantas se adaptam mais rapidamente ao meio na fase de germinação e nas primeiras etapas de desenvolvimento (Strogonov, 1964). De fato, na literatura são encontrados trabalhos com algodão (Inogamova, 1972), trigo e cevada (Manchanda \& Bhandhari, 1976), reportando que o pré-tratamento salino de sementes tem conferido, a essas plantas, o fenômeno de "hardening", traduzido para o português como "endurecimento" salino, resultando em maior capacidade de adaptação da cultura à salinidade em campo; em alface não se encontrou registro nesse sentido.

Diante da carência de resultados de pesquisa com a cultura da alface, sobretudo na região Nordeste, propôs-se, com este trabalho, estudar o rendimento da alface, cv. 'Elba', a mais plantada na região, em diferentes níveis de CE da água de irrigação, a partir de mudas produzidas com e sem estresse salino.

\section{MATERIAL E MÉTODOS}

O experimento foi conduzido em vasos, sob proteção de cobertura plástica, em instalações da Universidade Federal da Paraíba (UFPB), Campus II, em Campina Grande, PB, no período de dezembro de 1999 a fevereiro de 2000.

$\mathrm{O}$ ensaio foi instalado em delineamento estatístico inteiramente casualizado, com dez tratamentos e três repetições, arranjados em esquema fatorial 5 × 2, sendo cada parcela experimental constituída de um vaso. Os tratamentos resultaram da combinação de dois fatores: salinidade da água de irrigação (CEa) em 5 níveis $\left(\mathrm{S}_{1}=0,3 ; \mathrm{S}_{2}=1,0 ; \mathrm{S}_{3}=1,7 ; \mathrm{S}_{4}=2,4\right.$ e $\mathrm{S}_{5}=3,1 \mathrm{dS} \mathrm{m}^{-1}$ ) e tipos de mudas, produzidas com e sem estresse salino $\left(\mathrm{M}_{1}\right.$ - utilizando-se de água com $\mathrm{CE}$ de $0,3 \mathrm{dS} \mathrm{m}^{-1}$ e $\mathrm{M}_{2}$ com $\mathrm{CE}$ de $\left.3,1 \mathrm{dS} \mathrm{m}^{-1}\right)$.
Foi utilizada a cultivar de alface (Lactuca sativa L.) 'Elba', de folhas caracteristicamente crespas, e que não formam cabeça repolhuda. As mudas de 46 dias foram transplantadas no dia 4 de janeiro de 2000, sendo quatro mudas por vaso. Foram utilizados vasos de PVC (semicircular) com capacidade de $21,21 \mathrm{~L}$, conectados na base a um recipiente plástico com capacidade de $3 \mathrm{~L}$, para coleta da lâmina de drenagem.

O material de solo utilizado foi um tipo Podzólico "francoarenoso", proveniente de Campina Grande, PB, não salino e não sódico, cujas características físicas, químicas e hídricas determinadas no Laboratório de Irrigação e Salinidade (LIS) da UFPB, de acordo com as metodologias propostas por Richards (1954), constam na Tabela 1.

Tabela 1. Características físicas, químicas e hídricas do material de solo usado

\begin{tabular}{|c|c|}
\hline Atributo & Valor \\
\hline Densidade aparente, $\mathrm{kg} \mathrm{dm}^{-3}$ & 1,37 \\
\hline Classificação textural & Franco-arenoso \\
\hline \multicolumn{2}{|l|}{ Extrato de saturação: } \\
\hline $\mathrm{pH}$ & 4,54 \\
\hline $\mathrm{CE}, \mathrm{dS} \mathrm{m}{ }^{-1}$ a $25^{\circ} \mathrm{C}$ & 0,50 \\
\hline RAS, $\left(\mathrm{mmol} \mathrm{L}^{-1}\right)^{0,5}$ & 1,84 \\
\hline Classificação para salinidade/sodicidade & Não salino, não sódico \\
\hline \multicolumn{2}{|l|}{ Complexo sortivo, $\mathrm{cmol}_{\mathrm{c}} \mathrm{kg}^{-1}$} \\
\hline $\mathrm{H}+\mathrm{Al}$ & 2,72 \\
\hline $\mathrm{Ca}$ & 0,38 \\
\hline $\mathrm{Mg}$ & 0,74 \\
\hline $\mathrm{Na}$ & 0,20 \\
\hline K & 0,06 \\
\hline Capacidade de troca de cátions (CTC) & 4,10 \\
\hline Saturação de bases (V), \% & 33,66 \\
\hline Percentagem de sódio trocável (PST) & 4,88 \\
\hline \multicolumn{2}{|l|}{ Retenção de umidade, $\mathrm{g} \mathrm{kg}^{-1}$} \\
\hline $10,13 \mathrm{kPa}$ & 87,20 \\
\hline $1519,87 \mathrm{kPa}$ & 27,3 \\
\hline
\end{tabular}

Realizou-se calagem mediante o método da "saturação de bases" para elevar o $\mathrm{pH}$ do material de solo original $(4,54)$ a 6,25 $\left(\mathrm{pH}_{\text {provável }}=4,5+0,025 \mathrm{~V}\right.$, conforme Osaki, 1991) através da elevação da percentagem de saturação de bases $(33,66 \%)$ para $70 \%$ (Osaki, 1991). Estimou-se a quantidade de carbonato de cálcio pelo referido método e, a partir daí, a equivalência, em termos de hidróxido de cálcio, o corretivo utilizado. A dose do produto utilizado (cal hidratada) foi de $0,47 \mathrm{~g} \mathrm{~kg}^{-1}$ de solo, levando-se em consideração a pureza do produto (85\%).

Foi realizada adubação construtiva de fertilidade para fósforo e potássio, de acordo com metodologia descrita por Lopes \& Guidolin (1989); no caso de fósforo, objetivou-se elevar a quantidade deste elemento no material de solo de 1,9 para $12 \mathrm{mg} \mathrm{kg}^{-1}$, utilizando-se de $0,64 \mathrm{~g}$ de superfosfato simples por $\mathrm{kg}$ de solo, levando em conta uma eficiência de adubação fosfatada de $20 \%$ e para potássio, a adubação teve o objetivo de elevar para 3\% a participação deste elemento na CTC efetiva a $\mathrm{pH} 6,25$, sendo aplicados $17,6 \mathrm{mg}$ de $\mathrm{KCl} \mathrm{kg}^{-1}$ de solo.

Houve adição de húmus de minhoca ao solo, em quantidade suficiente para elevar o teor de matéria orgânica (MO) de 6 para $25 \mathrm{~g} \mathrm{~kg}^{-1}$. Para o enchimento dos $20 \mathrm{~cm}$ da parte superior dos recipientes, a adição de MO foi de um terço (base volume), em 
função da natureza do sistema radicular dessa olerícola, exigindo solos friáveis para boa produção (Filgueira, 1982). A seguir, realizou-se desinfeção e desinfestação do substrato com "brometo de metila", na dose recomendada pelo fabricante, ou seja, $150 \mathrm{~mL}$ do produto por metro cúbico de solo.

A adubação de fundação com 'fósforo' foi realizada com $10 \mathrm{~g} \mathrm{vaso}^{-1}$ de superfosfato simples, incorporados à camada 0-20 cm, com base na recomendação de $120 \mathrm{~kg} \mathrm{ha}^{-1}$ de $\mathrm{P}_{2} \mathrm{O}_{5}$, contida em Filgueira (1982). As adubações N-K, em cobertura, foram efetuadas através de dez aplicações no solo, de solução de nitrato de potássio $\left(1,6 \mathrm{~g} \mathrm{~L}^{-1}\right)$ na dose de $100 \mathrm{~mL}$ vaso $^{-1}$, sendo o fornecimento de nitrogênio suplementado por seis aplicações de $50 \mathrm{~mL}$ vaso $^{-1}$ de solução de uréia a $2,5 \mathrm{~g} \mathrm{~L}^{-1}$. As quantidades de $\mathrm{N}$ e $\mathrm{K}_{2} \mathrm{O}$ se basearam nas recomendações de $60 \mathrm{~kg} \mathrm{ha}^{-1}$ de $\mathrm{N}$ em cobertura e $90 \mathrm{~kg} \mathrm{ha}^{-1}$ de $\mathrm{K}_{2} \mathrm{O}$. As aplicações foram iniciadas dez dias após o transplantio, quando se confirmou o pegamento das mudas, conforme recomendação de Osaki (1991) e realizadas diariamente.

As águas utilizadas nas irrigações foram preparadas mediante adição de $\mathrm{NaCl}, \mathrm{CaCl}_{2}$ e $\mathrm{MgCl}_{2}$, em quantidades determinadas através do programa computacional Soluções Salinas ${ }^{*}$, de forma a se obter a $\mathrm{CE}_{\mathrm{a}}$ desejada para cada tratamento, em termos equivalentes de 7:2:1 para $\mathrm{Na}, \mathrm{Ca}$ e $\mathrm{Mg}$, respectivamente, relação esta presente na maioria das águas utilizadas para irrigação no Nordeste (Medeiros, 1992).

As irrigações foram efetuadas diariamente, ao final de cada tarde, e cada tratamento tinha um volume de irrigação próprio, corrigido a cada dia, em função do percentual drenado, de forma a se obter $30 \%$ de lixiviação e corrigir o aumento da demanda de água, devido ao crescimento das plantas; assim, o volume de irrigação era calculado com base no volume evapotranspirado no dia anterior, dividido pelo fator ' 0,7 ', de forma a se restabelecer a umidade do solo à capacidade de campo e se obter, também, um volume médio de drenagem de aproximadamente $30 \%$. A fração de lixiviação adotada é uma aproximação da média dos valores calculados para cada nível salino de água de irrigação, de acordo com a equação recomendada por Ayers \& Westcot (1991), utilizando o valor de salinidade limiar para alface, contido em Maas \& Hoffman (1977).

O crescimento da cultura foi avaliado aos 10, 20 e 30 dias após o transplantio (DAT) das mudas. Na primeira época, os dados foram oriundos de duas plantas por parcela e, nas outras avaliações, de uma planta por parcela.

As três coletas foram realizadas no início da noite, sendo todas as medidas, à exceção da matéria seca, efetuadas tão logo a planta era colhida. Aos 10 e 20 DAT, apenas a parte aérea foi coletada, enquanto aos 30 DAT coletou-se também o sistema radicular. As variáveis estudadas (por planta) foram: fitomassa verde (FVPA) e seca (FSPA) da parte aérea, número de folhas (NF), fitomassa seca de raízes (FSR) e diâmetro médio da cabeça (DM), sendo as duas últimas avaliadas apenas na coleta final.

O efeito dos diferentes níveis de salinidade da água de irrigação e tipos de muda sobre o crescimento e produção da alface, foi analisado em esquema fatorial, mediante aplicação de análise de variância e teste "F" (Ferreira, 1991). Para o fator

\footnotetext{
* Programa computacional desenvolvido pelo primeiro autor, em linguagem VBA
}

"níveis de salinidade de água de irrigação" realizou-se análise de regressão polinomial (linear e quadrática) por se tratar de fator quantitativo e, para "tipos de muda", por ser qualitativo, aplicou-se o teste de Tukey (nível de 5\% de probabilidade) para comparação das médias, com base em Santos et al.(1998).

\section{RESULTADOS E DISCUSSÃO}

\section{Número de folhas (NF)}

De acordo com a análise de variância dos dados (Tabela 2), o número de folhas foi afetado pela salinidade da água de irrigação, em nível de $1 \%$ de probabilidade, nas três avaliações efetuadas (10, 20 e 30 DAT). Conforme os estudos de regressão, o efeito foi linear, havendo decréscimo relativo a $S_{1}$ para cada incremento unitário de CEa de 6,0, 5,7 e 8,7\%, aos 10, 20 e 30 DAT, respectivamente, refletindo o efeito negativo da salinidade sobre a emissão de folhas. As curvas de regressão, significativas em nível de $1 \%$ de probabilidade, constam na Figura 1 e as médias, para cada tratamento salino, estão apresentadas na Tabela 2 .

Tabela 2. Resumo da ANAVA e análise de regressão para número de folhas (NF) em épocas distintas do ciclo, aos 10, 20 e 30 dias após o transplantio (DAT) da alface

\begin{tabular}{|c|c|c|c|c|c|c|}
\hline \multirow{2}{*}{ Causa de Variância } & \multicolumn{6}{|c|}{ Época de Amostragem ( DAT) } \\
\hline & \multicolumn{2}{|l|}{10} & \multicolumn{2}{|l|}{20} & \multicolumn{2}{|l|}{30} \\
\hline & \multicolumn{6}{|c|}{ Teste F } \\
\hline Salinidade (S) & 7,19 & $* *$ & 5,56 & $* *$ & 7,44 & $* *$ \\
\hline Reg. Pol. Linear & 23,09 & $* *$ & 15,81 & $* *$ & 42,31 & $* *$ \\
\hline Reg. Pol. Quadr. & 0,24 & ns & 0,87 & ns & 0,01 & ns \\
\hline Desv. Reg. & 0,50 & ns & 0,08 & ns & 0,54 & ns \\
\hline Tipo de muda (M) & 21,95 & $* *$ & 1,58 & ns & 6,13 & $*$ \\
\hline $\mathrm{S} \times \mathrm{M}$ & 1,58 & ns & 0,21 & ns & 0,25 & ns \\
\hline QMResíduo & 0,51 & & 1,03 & & 15,27 & \\
\hline \multirow[t]{2}{*}{$\mathrm{CV}(\%)$} & 9,60 & & 7,35 & & 9,94 & \\
\hline & \multicolumn{6}{|c|}{ Médias } \\
\hline \multicolumn{7}{|l|}{ Salinidade } \\
\hline $\mathrm{S}_{1}$ & 8,17 & & 14,83 & & 44,67 & \\
\hline $\mathrm{S}_{2}$ & 7,83 & & 14,50 & & 42,00 & \\
\hline $\mathrm{S}_{3}$ & 7,50 & & 14,00 & & 40,00 & \\
\hline $\mathrm{S}_{4}$ & 6,92 & & 13,50 & & 35,50 & \\
\hline $\mathrm{S}_{5}$ & 6,92 & & 12,33 & & 34,33 & \\
\hline \multicolumn{7}{|l|}{ Tipo de muda } \\
\hline $\mathrm{M}_{1}$ & 7,90 & $\mathrm{a}$ & 14,07 & $\mathrm{a}$ & 41,07 & $\mathrm{a}$ \\
\hline $\mathrm{M}_{2}$ & 7,03 & $\mathrm{~b}$ & 13,60 & $\mathrm{a}$ & 37,53 & $\mathrm{~b}$ \\
\hline $\mathrm{dms}$ & 0,37 & & 0,77 & & 2,98 & \\
\hline
\end{tabular}

(*) Significativo a $5 \%$ e (**) a $1 \%$ de probabilidade; (ns) Não significativo; médias seguidas de mesma letra na vertical não diferem a $5 \%$ de probabilidade

Os poucos trabalhos encontrados na literatura, a respeito dos efeitos da salinidade sobre o crescimento e desenvolvimento da alface (Shannon et al., 1983; Cramer \& Spurr, 1986; Ferreira et al., 1998; Blanco et al., 1999; Gervásio et al., 2000), não fazem qualquer referência ao efeito dos sais sobre a emissão de folhas, porém, todos se reportam à redução de fitomassa da parte aérea, levando a crer que também nos referidos trabalhos tenha havido redução do NF com o incremento da salinidade.

Observando-se as médias de NF nas distintas épocas de avaliação em relação ao fator 'tipos de muda' (Tabela 2), verifica-se 


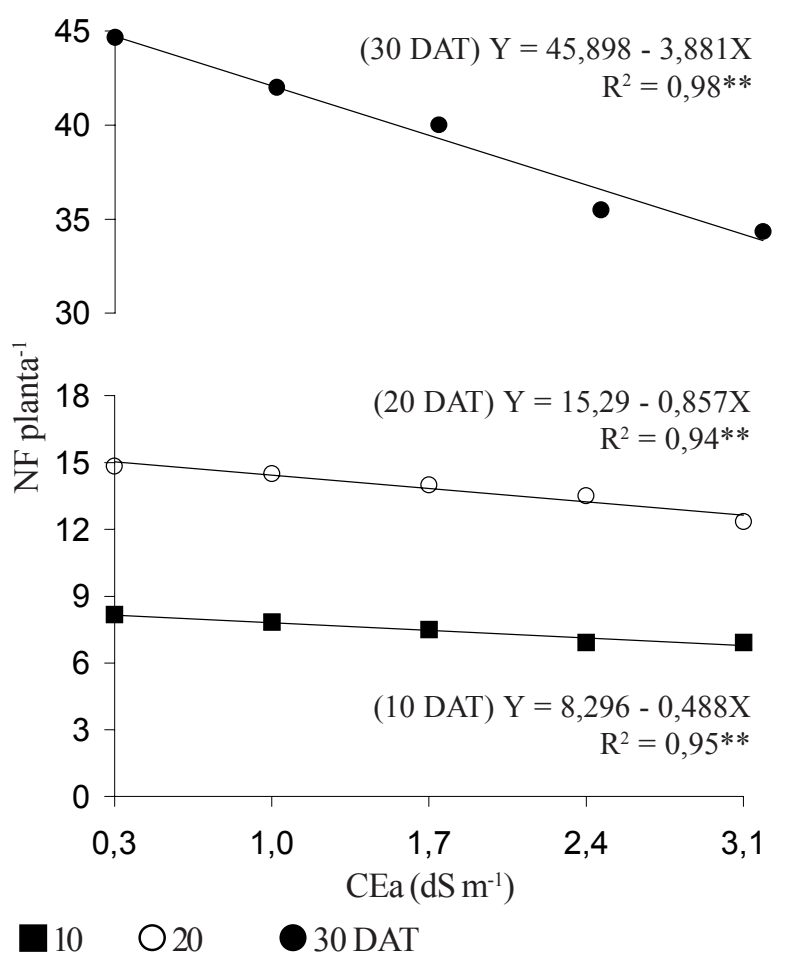

Figura 1. Número de folhas (NF) em função da condutividade elétrica da água de irrigação (CEa) aos 10, 20 e 30 dias após o transplantio (DAT) da alface

que as plantas oriundas de mudas produzidas sem estresse salino $\left(\mathrm{M}_{1}\right)$ formaram maior número de folhas em todas as amostragens, embora não tenha havido efeito significativo do fator 'tipos de muda' aos 20 DAT. Apesar de as plantas oriundas de $M_{1}$ terem formado maior NF ao longo do ciclo, nota-se, de forma geral, uma certa capacidade de recuperação das plantas $\mathrm{M}_{2}$; aos 10 DAT, o número médio de folhas produzidas por planta, oriunda da muda $\mathrm{M}_{2}$, era $11,0 \%$ inferior ao de $\mathrm{M}_{1}$, enquanto aos 30 DAT, aquele valor foi reduzido para $8,6 \%$. Vale salientar que por ocasião do transplantio, as mudas $\mathrm{M}_{2}$ tinham um NF médio 26,2\% inferior ao de $\mathrm{M}_{1}$ (Viana, 2000).

Apesar de se ter verificado efeito isolado do fator 'tipo de muda' (M) sobre o número de folhas/planta, o mesmo não foi interativo com os níveis de CEa estudados (Tabela 2), uma vez que o efeito da salinidade sobre o NF independeu do tipo de muda usado.

\section{Fitomassa verde (FVPA) e seca (FSPA) da parte aérea}

Assim como para o número de folhas, o fator 'salinidade da água de irrigação - $\mathrm{S}$ ' afetou $(\mathrm{p}<0,01)$ a fitomassa verde e seca da parte aérea (Tabela 3), com redução linear nas três avaliações (10, 20 e 30 DAT). De acordo com as análises de regressão, os decréscimos relativos (comparados a $\mathrm{S}_{1}$ ) para cada incremento unitário de CEa aos 10, 20 e 30 DAT foram de 13,4, 10,5 e 9,0\% para FVPA e de 13,8, 11,4 e 9,6\% para FSPA. No final do ciclo (30 DAT) os decréscimos ocorridos nos tratamentos $\mathrm{S}_{4}$ e $\mathrm{S}_{5}$, relativos a $S_{1}$, foram de 19,0 e 25,3\% para FVPA, e de 20,2 e $27,0 \%$ para FSPA, respectivamente. As curvas de regressão estão apresentadas na Figura 2.

Com base nos citados decréscimos, verifica-se que a tolerância da alface cv. Elba, frente ao aumento da salinidade da água de irrigação, foi crescente com o tempo; o fato, segundo Lima (1997) ocorre com a maioria das culturas, embora existam exceções, como o arroz, que é mais afetado durante o florescimento.

A redução linear de fitomassa da parte aérea, ocorrida neste trabalho quando a irrigação foi realizada com água de CE superior a $0,3 \mathrm{dS} \mathrm{m}^{-1}$ (Figura 2), está em concordância com os resultados obtidos por Gervásio et al. (2000) que também constataram redução de fitomassa da parte aérea com o aumento da $\mathrm{CEa}$ acima de $0,3 \mathrm{dS} \mathrm{m}^{-1}$, sendo que os níveis testados por esses

Tabela 3. Resumo da ANAVA e médias para fitomassa verde (FVPA) e seca (FSPA) da parte aérea, em três épocas do ciclo da alface, aos 10, 20 e 30 dias após o transplantio (DAT)

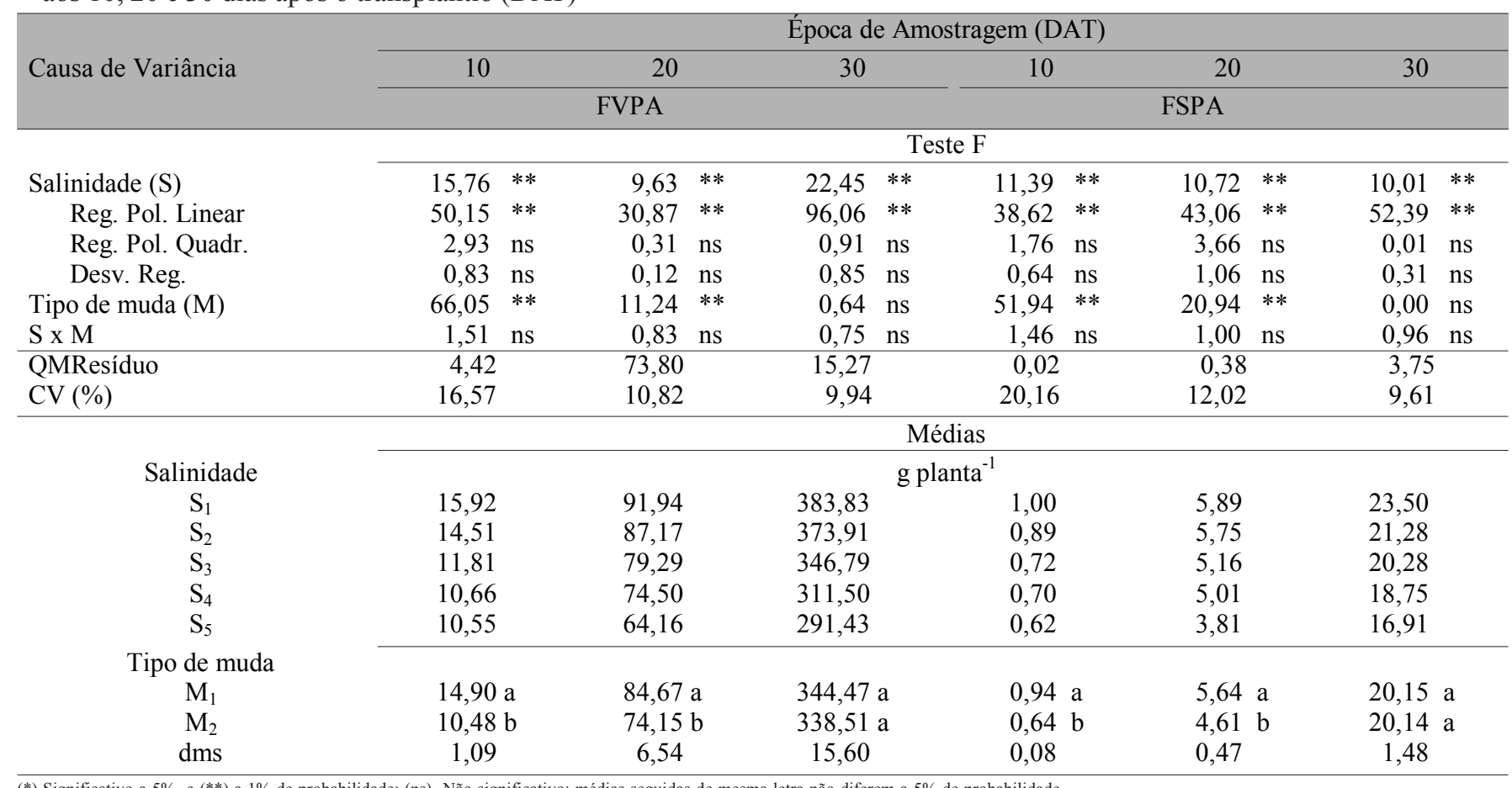

(*) Significativo a $5 \%$ e $\left(^{* *}\right)$ a $1 \%$ de probabilidade; (ns) Não significativo; médias seguidas de mesma letra não diferem a $5 \%$ de probabilidade 


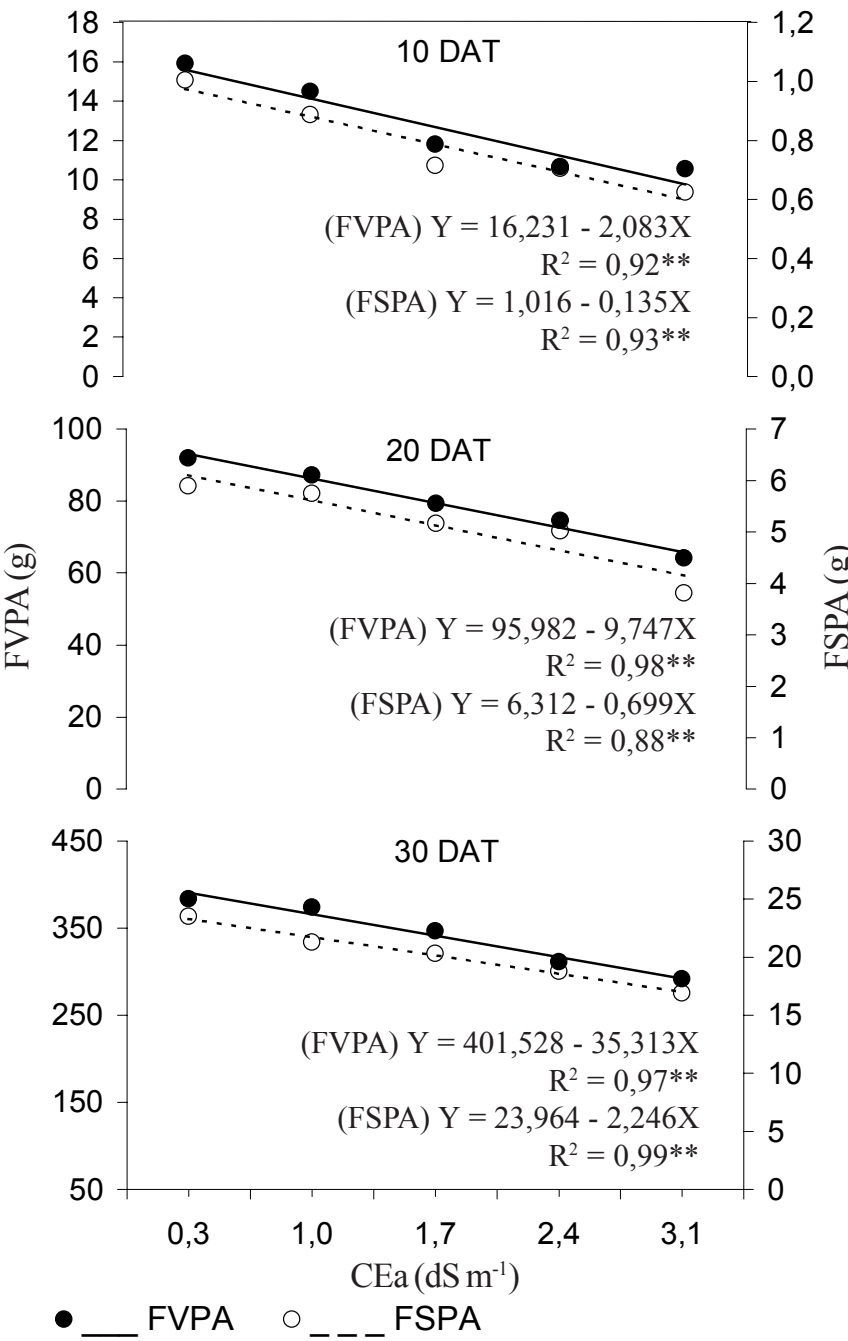

Figura 2. Fitomassa verde (FVPA) e seca (FSPA) da parte aérea da alface, em função da condutividade elétrica da água de irrigação (CEa) aos 10, 20 e 30 dias após o transplantio (DAT)

autores variaram de 0,18 a $6,00 \mathrm{dS} \mathrm{m}^{-1}$; em outros trabalhos com alface foi também verificado decréscimo de fitomassa, sob condições de estresse salino (Shannon et al., 1983; Cramer \& Spurr, 1986; Ferreira et al., 1998; Blanco et al., 1999).

O pré-tratamento salino (fator 'tipo de muda - M') afetou, em nível de $1 \%$ de probabilidade, a fitomassa verde e seca da parte aérea, aos 10 e $20 \mathrm{DAT}$, porém, por ocasião da colheita (30 DAT) não houve efeito significativo deste "fator" sobre as citadas variáveis (Tabela 3). Observa-se que as plantas, oriundas de mudas do tipo $\mathrm{M}_{2}$, tiveram crescente capacidade de recuperação em termos de produção de fitomassa da parte aérea; aos 10 DAT, a diferença de $\mathrm{M}_{2}$ em relação a $\mathrm{M}_{1}$, para FVPA foi de $29,6 \%$ e de $31,6 \%$ para FSPA; aos 20 DAT, as diferenças caíram para 12,4 e $18,2 \%$, respectivamente, chegando a $1,73 \mathrm{e}$ $0,03 \%$ aos 30 DAT. Desta forma, constata-se claramente que o estresse sofrido na fase de muda foi gradualmente superado durante o ciclo, de tal forma que, por ocasião da colheita, não mais havia diferença estatística em termos de fitomassa da parte aérea, entre as plantas oriundas de mudas produzidas sem $\mathrm{e}$ com estresse salino, $\mathrm{M}_{1}$ e $\mathrm{M}_{2}$, respectivamente.

Não se constatou efeito interativo entre os fatores estudados sobre a produção de fitomassa da parte aérea, nas três avaliações (Tabela 3); assim, o efeito depreciativo e linear da salinidade da água de irrigação sobre a produção de fitomassa verde e seca da parte aérea ocorreu de forma estatisticamente igual, nas plantas originadas de ambos os 'tipos de muda', ou seja, o efeito negativo da salinidade não dependeu do tipo de muda usada.

\section{Fitomassa seca de raiz (FSR) aos 30 DAT}

A fitomassa seca de raiz foi afetada $(p<0,01)$ pela salinidade da água de irrigação (Tabela 4), sendo quadrático o efeito, segundo os estudos de regressão. Os decréscimos, em relação a $\mathrm{S}_{1}$, foram de $32,2,54,5,66,8$ e $69,1 \%$, para $\mathrm{S}_{2}, \mathrm{~S}_{3}, \mathrm{~S}_{4}$ e $\mathrm{S}_{5}$, respectivamente; a equação de regressão obtida consta na Figura 3. Comparando-se o decréscimo de FSR, da ordem de 69,1\% no nível mais alto de salinidade, com o anteriormente discutido para FSPA, que foi de $27,0 \%\left(\mathrm{~S}_{5}\right)$ aos $30 \mathrm{DAT}$, constata-se que, no final do ciclo, o maior prejuízo da salinidade ocorreu em termos de raiz.

Tabela 4. Resumo da ANAVA e médias para fitomassa seca de raiz (FSR), matéria seca total (FST) e diâmetro médio da cabeça (DM) aos 30 dias após o transplantio da alface

\begin{tabular}{|c|c|c|c|c|}
\hline \multirow{2}{*}{ Causa de Variância } & \multicolumn{2}{|l|}{ FSR } & \multicolumn{2}{|c|}{$\mathrm{DM}$} \\
\hline & \multicolumn{4}{|c|}{ Teste F } \\
\hline Salinidade (S) & 29,88 & $* *$ & 15,23 & $* *$ \\
\hline Reg. Pol. Linear & 250,70 & $* *$ & 61,35 & $* *$ \\
\hline Reg. Pol. Quadr. & 29,22 & $* *$ & 0,35 & ns \\
\hline Desv. Reg. & 0,24 & ns & 0,32 & ns \\
\hline Tipo de muda (M) & 8,90 & $* *$ & 14,87 & $* *$ \\
\hline $\mathrm{S} \times \mathrm{M}$ & 1,59 & ns & 1,50 & ns \\
\hline QMResíduo & 0,44 & & 1,40 & \\
\hline \multirow[t]{2}{*}{ CV $(\%)$} & 23,35 & & 2,92 & \\
\hline & \multicolumn{4}{|c|}{ Médias } \\
\hline Salinidade & $\mathrm{g}$ & & $\mathrm{cm}$ & \\
\hline $\mathrm{S}_{1}$ & 5,15 & & 42,89 & \\
\hline $\mathrm{S}_{2}$ & 3,42 & & 41,89 & \\
\hline $\mathrm{S}_{3}$ & 2,30 & & 40,28 & \\
\hline $\mathrm{S}_{4}$ & 1,79 & & 39,05 & \\
\hline $\mathrm{S}_{5}$ & 1,54 & & 38,39 & \\
\hline \multicolumn{5}{|l|}{ Tipo de muda } \\
\hline $\mathrm{M}_{1}$ & 3,20 & $\mathrm{a}$ & 39,67 & $\mathrm{~b}$ \\
\hline $\mathrm{M}_{2}$ & 2,48 & $\mathrm{~b}$ & 41,33 & $\mathrm{a}$ \\
\hline $\mathrm{dms}$ & 0,50 & & 0,90 & \\
\hline
\end{tabular}

(*) Significativo a $5 \%$ e $\left({ }^{* *}\right)$ a $1 \%$ de probabilidade; (ns) Não significativo; médias seguidas de mesma letra não diferem a $5 \%$ de probabilidade

Também se verificou efeito isolado do fator 'tipo de muda M', sobre a FSR, em nível de 1\% de probabilidade (Tabela 4); as plantas oriundas de mudas produzidas sem estresse salino $\left(\mathrm{M}_{1}\right)$ tiveram, ao final do ciclo, fitomassa radicular estatisticamente superior à das plantas provenientes de mudas produzidas sob condições de estresse $\left(\mathrm{M}_{2}\right)$. O decréscimo de FSR ocorrido em $\mathrm{M}_{2}$, relativo a $\mathrm{M}_{1}$, foi de $22,6 \%$, ao passo que para FSPA, como já discutido, não houve diferença significativa entre $M_{1}$ e $M_{2}$, ficando evidenciado, assim, que o maior efeito depreciativo da salinidade, ao final do ciclo, ocorreu em termos de FSR, ainda que o estresse tenha ocorrido na fase de muda.

Apesar de ter havido efeito isolado dos fatores estudados, estatisticamente significativos, sobre a fitomassa seca das raízes (Tabela 4), não foi ele interativo, uma vez que a redução quadrática da fitomassa seca de raiz com o aumento da salinidade, ocorreu tanto nas plantas oriundas de mudas $\mathrm{M}_{1}$ quanto nas de $\mathrm{M}_{2}$. 


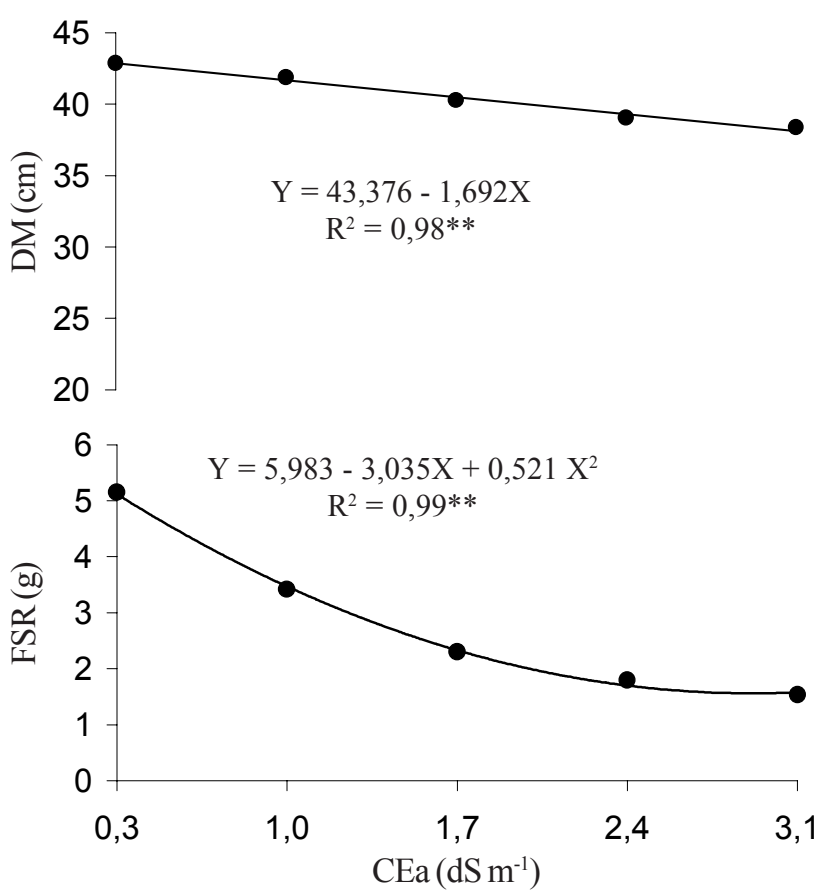

Figura 3. Fitomassa seca de raiz (FSR) e diâmetro médio da cabeça (DM) da alface, em função da condutividade elétrica da água de irrigação (CEa), aos 30 dias após o transplantio (DAT)

Cramer \& Spurr (1986) e Shannon et al. (1983) trabalhando com alface, constataram menor sensibilidade para o sistema radicular que para a parte aérea, sob condições de salinidade. Outros autores, trabalhando com espécies diferentes, relatam maior sensibilidade do sistema radicular em condições de estresse salino (Amorim, 1994; Marinho et al., 1998; Souza, 1999).

\section{Diâmetro médio da cabeça (DM) aos 30 DAT}

De acordo com a análise de variância, a salinidade da água de irrigação afetou o diâmetro médio da cabeça da alface (cv. Elba) em nível de 1\% de probabilidade (Tabela 4). Pelos estudos de regressão, nota-se que o efeito foi linear e decrescente (Figura 3 ), havendo decréscimo relativo (comparado a $\mathrm{S}_{1}$ ) de $4,0 \%$ para cada incremento unitário de $\mathrm{CEa}$; desta forma, os decréscimos relativos estimados para os níveis mais altos de salinidade foram de 8,3 e 11,0\%, para $\mathrm{S}_{4}$ e $\mathrm{S}_{5}$, respectivamente; portanto, o diâmetro da cabeça de alface teve comportamento inversamente proporcional ao incremento de salinidade. Ferreira et al. (1998) também encontraram decréscimo do diâmetro de cabeça em alface, com o aumento da salinidade da água de irrigação.

O fator 'tipos de muda' produziu, também, efeito significativo sobre o diâmetro médio de cabeça da alface, conforme pode ser constatado na Tabela 4, onde está apresentada a análise de variância dos dados de DM. De acordo com o teste de comparação de médias (Tukey a 5\% de probabilidade) também contido na referida tabela, o diâmetro médio da cabeça de plantas originadas de $M_{1}$ diferiu do obtido para as de $M_{2}$; portanto, as plantas oriundas de mudas produzidas em condições de estresse salino $\left(\mathrm{M}_{2}\right)$ tiveram DM estatisticamente superior $(+4 \%)$. De fato, as plantas oriundas de mudas $M_{1}$ desenvolveram cabeça mais compacta (observação visual), com folhagem mais ereta, sendo por isso menor o diâmetro de cabeça, mesmo assim foi observado maior fitomassa da parte aérea (Tabela 4). Entre os níveis de CEa estudados (S), o DM decresceu com o aumento da salinidade, como já discutido, porém, isto se deveu ao maior crescimento da alface, quanto menor era a salinidade, apesar de as plantas submetidas aos níveis mais baixos de CEa terem formado cabeça mais compacta; neste caso, a maior contribuição para o DM foi, de fato, o maior crescimento da parte aérea, quanto menor era a salinidade, e não o posicionamento da folhagem. Cermeño (s.d.) apud por Gervásio et al. (2000) constatou, também, formação de cabeças pouco consistentes, quando a alface era submetida a estresse salino.

Os efeitos dos fatores 'salinidade' e 'tipos de muda' sobre o diâmetro médio de cabeça da alface (cv. Elba) ocorreram isoladamente (Tabela 4), sem haver efeito interativo, devido ao DM ter decrescido com o aumento da salinidade, de forma estatisticamente igual, em ambos os níveis do fator 'tipos de muda'.

\section{CONCLUSÕES}

1. O estresse salino produz efeito negativo, sendo linear e decrescente desde $\mathrm{CEa}$ de $0,3 \mathrm{dS} \mathrm{m}^{-1}$ para as variáveis número de folhas, diâmetro da cabeça, fitomassa verde e seca da parte aérea. A fitomassa seca de raiz decresce de forma quadrática, com o incremento da CEa acima de $0,3 \mathrm{dS} \mathrm{m}^{-1}$.

2. O efeito da salinidade, ao final do ciclo vegetativo da alface, é mais intenso sobre o sistema radicular que sobre a parte aérea.

3. O uso de mudas produzidas com água de 0,3 ou $3,1 \mathrm{dS} \mathrm{m}^{-1}$ não tem influência posterior sobre a produção da alface.

4. O rendimento final da alface, cv. Elba, decresce linearmente com o aumento da salinidade, com redução de $9,0 \%$, por incremento unitário de condutividade elétrica da água de irrigação - CEa.

\section{LITERATURA CITADA}

Amorim, J.R.A. Comportamento do alho (Allium sativum L.) sob diferentes níveis de salinidade da água de irrigação. Campina Grande: UFPB, 1994. 97p. Dissertação Mestrado

Araújo Filho, J.B.; Gheyi, H.R; Azevedo, N.C.; Santos, J.G.R. Efeitos da salinidade no crescimento e no teor de nutrientes em cultivares de bananeira. Revista Brasileira de Ciência do Solo, Campinas, v.19, p.417-422, 1995.

Ayers, R.S.; Westcot, D.W. A qualidade da água na agricultura. Campina Grande: UFPB, 1991, 218p. Estudos da FAO Irrigação e Drenagem, 29 revisado.

Blanco, F.F.; Medeiros, J.F.; Folegatti, M.V. Produção da alface (Lactuca sativa L.) em ambiente protegido sob condições salinas. In: Congresso Brasileiro de Engenharia Agrícola, 28, Pelotas, 1999. Anais... CD-ROM. Pelotas: SBEA, 1999.

Cramer, G.R.; Spurr, A.S. Responses of lettuce to salinity. I. Effects of $\mathrm{NaCl}$ and $\mathrm{Na}_{2} \mathrm{SO}_{4}$ on growth. Journal of Plant Nutrition, New York, v.9, n.2, p.115-130, 1986.

Fageria, N.K. Solos tropicais e aspectos fisiológicos das culturas. Brasília: EMBRAPA/DPU, 1989.425p. EMBRAPA/ CNPAF. Documento, 18

Fageria, N.K.; Barbosa Filho, M.P.; Gheyi, H.R. Avaliação de cultivares de arroz para tolerância à salinidade. Pesquisa Agropecuária Brasileira, Brasília, v.16, n.5, p.677-681, 1981. 
Ferreira, P.V. Estatística experimental aplicada à agronomia. Maceió: UFAL/EDUFAL/FUNDEPES, 1991.437p.

Ferreira, Y.R.P.; Duarte, S.N.; Miranda, J.H.; Medeiros, J.F. Efeito da salinidade de água de irrigação e da lâmina de lixiviação na cultura da alface (Lactuca sativa L.) cultivada em vasos. In: Congresso Brasileiro de Engenharia Agrícola, 27, Poços de Caldas, 1998. Anais... Poços de Caldas: SBEA, 1998. p.106-108.

Filgueira, F.A.R. Cichoriáceas. In: Manual de olericultura. $2^{\text {a }}$ ed. São Paulo: Agronômica Ceres, 1982. p. 77-86.

Gervásio, E.S.; Carvalho, J.A.; Santana, M.J. Efeito da salinidade da água de irrigação na produção da alface americana. Revista Brasileira de Engenharia Agrícola e Ambiental, Campina Grande, PB, v.4, n.1, p.125-128, 2000.

Inogamova, M.T. Growth, development and productivity of cotton grown on saline soil. Uchenye Zapiski Tashkents Pedagogicheskii Institut, v.92, p.122-127, 1972.

Lima, L.A. Efeito de sais no solo e na planta. In: Gheyi, H.R.; Queiroz, J.E. \& Medeiros, J.M. (ed). Manejo e controle da salinidade na agricultura. Campina Grande: UFPB/SBEA, 1997.

Lopes, A.S.; Guidolin, J.A. Interpretação de análise de solo: conceitos e aplicações. $3^{\mathrm{a}}$ ed. Comitê de pesquisa/Técnico/ ANDA. São Paulo: 1989. 50p.

Maas, E.V.; Hoffman, G.J. Crop salt tolerance - current assessment. Journal of Irrigation and Drainage Division, New York, v.103, n.IR2, p.115-134, 1977.

Manchanda, H.R.; Bhandhari, D.K. Effect of presoaking of seeds in salt solutions on yield of wheat and barley irrigated with highly saline waters. Journal Indian Society of Soil Science, New Delhi, v.24, p.432-435, 1976.

Marinho, F.J.L.; Fernandes, P.D.; Gheyi, H.R. Desenvolvimento inicial do abacaxizeiro, cv. Smooth Cayenne, sob diferentes condições de salinidade da água. Revista Brasileira de Engenharia Agrícola e Ambiental, Campina Grande, PB, v.2, n.1, p.1-5, 1998.
Medeiros, J.F. Qualidade de água de irrigação e evolução da salinidade nas propriedades assistidas pelo 'GAT' nos estados de RN, PB e CE. Campina Grande: UFPB, 1992. 173p. Dissertação Mestrado

Nadal, R.; Guimarães, D.R.; Biasi, J. Olericultura em Santa Catarina: aspectos técnicos e econômicos. Florianópolis: EMPASC, 1986. 187p.

Osaki, F. Calagem e adubação. $2^{\circ}$ ed. rev. ampliada. Campinas, SP: Instituto Brasileiro de Ensino Agrícola, 1991. 503p.

Richards, L.A. (ed.). Diagnosis and improvement of saline and alkali soils. Washington: United States Salinity Laboratory, 1954, 160p. USDA. Agriculture Handbook, 60.

Santos, J.W. dos; Moreira, J. de A.N.; Beltrão, N.E. de M. Avaliação do emprego dos testes de comparação de médias na revista Pesquisa Agropecuária Brasileira (PAB) de 1980 a 1994. Pesquisa Agropecuária Brasileira, Brasília, v.33, n.3, p.225-230, 1998 .

Shannon, M.C.; McCreigth, J.D.; Draper, J.H. Screening test for salt tolerance in lettuce. Journal of the American Society for Horticultural Science, Mount Vermon, v.108, n.2, p.225-230, 1983.

Souza, R.F.A. Germinação e desenvolvimento inicial de plantas de melão (Cucumis melo L.) e melancia (Citrullus vulgaris) sob diferentes condições de salinidade da água de irrigação. Campina Grande: UFPB, 1999. 96p. Dissertação Mestrado.

Strogonov, B.P. Physiological bases of salt tolerance of plants. Jerusalém, Israel: Programe of Scientific Translation, 1964. $279 p$.

Viana, S.B.A. Estresse salino na germinação, fase de muda e produção de alface (Lactuca sativa L.). Campina Grande: UFPB, 2000. 127p. Dissertação Mestrado

Wilcox, L.V.; Durum, W.H. Quality of irrigation water. In: Hagan, R.M.; Haise, R.H.; Edminister, T.W. (eds.). Irrigation of agricultural lands. Madison: American Society of Agronomy, 1967. cap.9, p.104-122. Agronomy, 11 